\title{
Coats' disease in Tanzania: first case report and literature review
}

\author{
Rugwizangoga, Belson; Mwabili, Theresia; Meyer, Peter; Kitinya, James
}

Muhimbili National Hospital, Scanlan, Trisha; Muhimbili National Hospital, Paediatric Oncology

Muhimbili University of Health and Allied Sciences

\begin{abstract}
Background:

Coats' disease is an exudative retinal detachment with vascular telangiectasis occurring mostly in male children, the age group most affected by retinoblastoma.
\end{abstract}

Objectives:

To compare the differential diagnoses of Coats' disease

To establish recommendation to early disease detection.

Materials and Methods:

A 3-year-old female child was referred to Muhimbili National Hospital (MNH), Tanzania, in September 2011. She had presented at the peripheral hospital with gradual onset of left eye leukocoria for 1 year and pain for 2 months. B-scan showed a mass in the left eye. A clinical diagnosis of retinoblastoma was made. Left eye enucleation was performed; the patient was referred to $\mathrm{MNH}$, with the enucleated specimen.

\section{Results:}

Brain and orbits scan revealed no residual tumour. The globe measured $2 \times 1.8 \mathrm{~cm}$, the optic nerve stump measured 3 mm. A whitish mass filled the vitreous, with complete retinal detachment. Microscopy showed retinal gliosis, detachment with sub retinal PAS positive exudates, vacuolation and cholesterol clefts. Foreign body giant cells were present; telangiectatic thinwalled blood vessels were identified. Clinico-pathological findings were of stage 4 Coats' disease.

\section{Conclusion:}

Coats' disease is an important differential diagnosis of retinoblastoma. Delay to detect Coats' disease leads to vision loss which necessitates eye enucleation as was in this child.

Keywords: Coats' disease, Tanzania

DOI: http://dx.doi.org/10.4314/ahs.v14i3.37

\section{Background}

Coats' disease is an exudative retinopathy associated with retinal detachment and vascular telangiectatic foci. This disease was first described in 1908 by Georges Coats (1). It is more common in young male children (2; 3). It is associated with somatic mutation in NDP gene located on chromosome Xp11.2 (4).

Coats' disease is characterized by vascular telangiectasis in the peripheral area of retina, which causes leakage of exudate in retinal outer layers and sub retinal space,

\section{Corresponding Author:}

Belson Rugwizangoga, MD, MMed

Department of Pathology, Muhimbili University of Health and Allied Sciences (MUHAS) /

Department of Clinical Biology, University of

Rwanda (UR) School of Medicine,

P.O.Box 217 Butare, Rwanda

Telephone Number: +250788546597

E-mail: belson777@gmail.com leading to the retinal detachment. The presence of the unilateral leukocoria and the growth of the lesion in sub retinal layers mimic an exophytic retinoblastoma; this makes Coats' disease an important differential diagnosis to the unilateral retinoblastoma $(2 ; 3)$. There is a scarcity of reports on Coats' disease in Africa and no prior cases have been in Tanzania. We herein report a case of Coats' disease in a 3-year old girl, followed by a brief literature review.

\section{Case report}

\section{Medical history}

We report a case of a 3-year old female child. She presented with left eye leukocoria for 1 year, pain associated with scratching for 2 months, left eye proptosis and redness for 1 month. The symptoms were of gradual onset, progressive, without aggravating factors. No eye discharge or bleeding was associated. The familial and personal medical history was unremarkable; 
the stature, body mass and mental growth were normal. The child was brought to the nearby District Hospital which referred her to a Rehabilitation Centre without a firm diagnosis being made.

\section{Clinical and Para clinical findings}

The examination performed at the Rehabilitation Centre revealed left leukocoria and vision loss. B-scan ultrasound showed left eye posterior mass. The right eye and other systems were normal.

\section{Patient management}

The clinical impression was left eye retinoblastoma. Left eyeball enucleation was performed. The patient was referred to Muhimbili National Hospital (MNH), with the eyeball specimen in fixative, for diagnosis and management.

The patient was received at MNH 3 days after enucleation; the full blood picture showed mild microcytic and hypochromic anaemia with anisocytosis. The comprehensive chemistry panel (CCP) was unremarkable. The enzyme-linked immunosorbent assay (ELISA) test was negative for the human immunodeficiency virus (HIV). The computer tomography scan of the brain showed a normal brain without evident metastatic lesion; ventricles and sulci were normal. Bone marrow aspirate (BMA) showed no evidence of malignant infiltrate. The peripheral blood film showed was unremarkable. The patient was admitted for post-operation management, waiting for the histology diagnosis.

\section{Gross examination of specimen}

The eyeball specimen was received fixed in 10\% buffered formalin. Grossly, the eyeball had no lateralizing signs. A stump of the optic nerve was attached, measuring $3 \mathrm{~mm}$ of length. The globe itself measured $2 \times 1.8 \mathrm{~cm}$. Cut sections of the globe showed a soft white mass filling the vitreous; the mass involved the entire retina (Figure 1A).

Figure1. Morphological findings in our reported case of Coats' disease. A: Gross cut section of the eyeball, showing a whitish mass filling the vitreous.

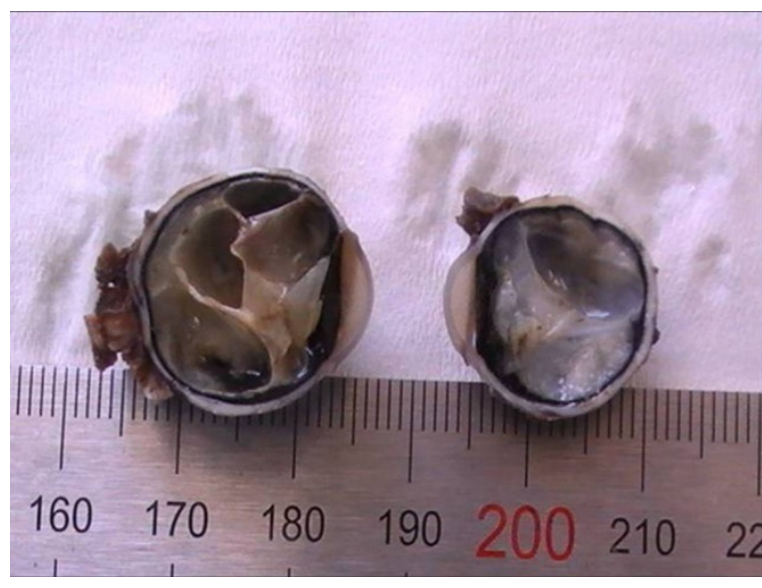

The cornea was misty but the lens was normal. No obvious optic nerve involvement was noted. As the microscopy of the primary slides showed no evidence of retinoblastoma, the whole eyeball was subsequently sectioned and processed, to exclude the possibility of retinoblastoma.

\section{Microscopy}

The sections from the eyeball, stained with Haematoxylin and Eosin (H\&E) showed flocculation of the cornea without inflammation, consistent with oedema. The iris and lens were normal. Both anterior and posterior chambers of the aqueous humour were empty and normal. Gliosis at the junction of the iris and traction membrane was evident.

There was total retinal detachment with intra- and subretinal exudate (Figure 1B).

B: Eyeball whole mount showed retinal detachment with sub retinal exudates, Haematoxylin and Eosin (H\&E) stain.

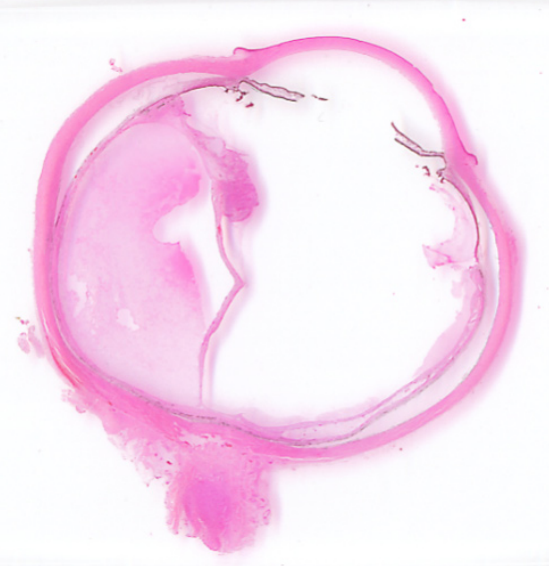


The whole retina showed thickening, serous vacuolation with cholesterol clefts (Figure 1C) and telangiectatic blood vessels on $H \& E$ sections and highlighted by CD31 immunoperoxidase staining (not shown). Macular retinal ganglion cell axonal count was not performed because the macula was involved by the exudative retinal detachment.

C: Retinal serous vacuolation with cholesterol clefts (H\&E, x 100).

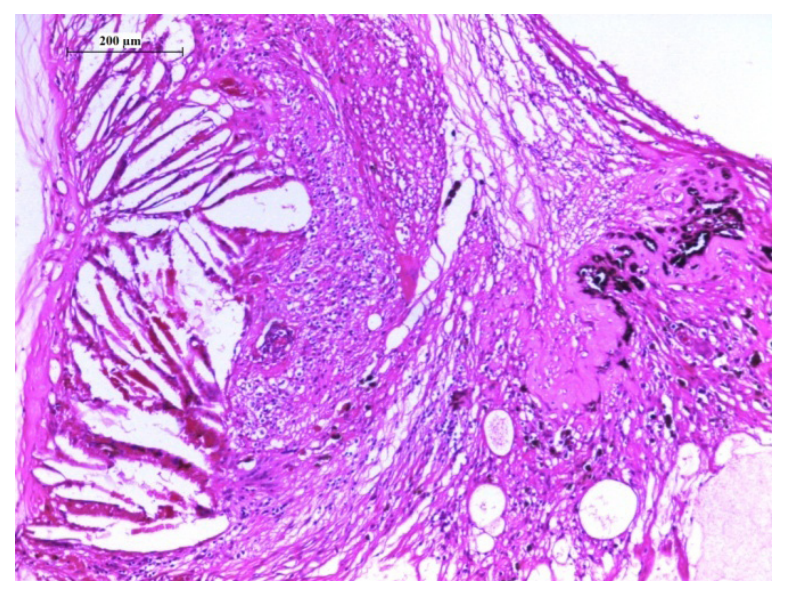

The optic nerve microscopically appeared mildly atrophic; optic nerve axon count was not performed. The exudate was Periodic Acid Schiff (PAS) positive (Figure 1D). A consultation of an Ophthalmic Pathologist at University of Basel, Switzerland through iPath confirmed the diagnosis of Coats' disease, stage 4.

D: Sub retinal exudate and retinal vacuolated foci were PAS positive (PAS, X 400).

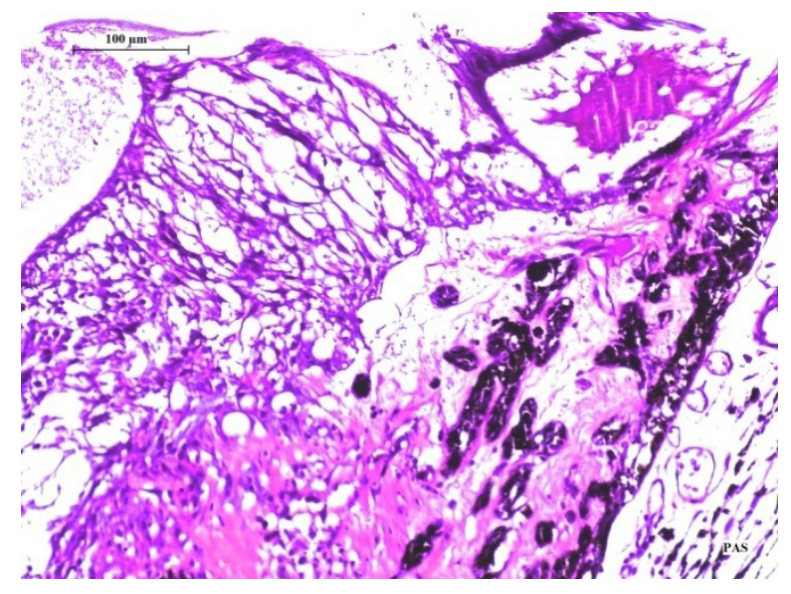

\section{Discussion and literature review}

Coats' disease is a rare non-hereditary ocular disease, with no systemic manifestation. It was first described by George Coats in 1908 (1). It is more common in children than in adults, and has a clear male predominance $(2 ; 3$; 4; 5). A prospective population-based study of Coats' disease in the United Kingdom collected 55 cases during 2008; all the cases were unilateral and $41 \%$ presented with Coats' disease stage $2 \mathrm{~A}$ at diagnosis (6). African data are scarce; a study done in 2011 on incidence and distribution of retinoblastoma in Kenya for the period 2006-2007, revealed two cases of Coats' disease that were misdiagnosed as retinoblastoma, but their stages were not specified (7).

\section{Genetics}

About 100 NDP mutations are recognized; these mutations include the germ-line mutation in Xp11.3 causing Norrie disease (8). Coats' disease is associated with somatic mutation in Norrie Disease Protein (NDP) gene located on chromosome Xp11.2, leading to a deficiency of norrin (4). Norrin is a protein product of the NDP gene, which is critical for normal retinal vasculogenesis (8). A somatic NDP mutation causing Coats' disease is thought to occur within cells of neuroectodermal origin at a stage of retina development; the high male: female ratio is thought to result from partial escape of $\mathrm{X}$-inactivation in females (4).

\section{Pathogenesis and histology}

Coats' disease presents with vascular telangiectasis in the peripheral area of retina; this causes the leakage of an exudate in retinal outer layers and sub retinal space, which leads to the retinal detachment; the exudate stains positive with periodic acid Schiff (PAS), and is rich in lipids and foamy macrophages; cholesterol clefts are seen in the sub retinal spaces (3). Vascular growth factor (VEGF) plays a central role in the genesis of telangectasia and increased vascular permeability, as well as in sub retinal space infiltration by macrophages (9). In fact, there are significant correlations between VEGF immunoreactivity in retinal endothelial cells and the presence of retinal vascular abnormalities, VEGF Immunoreactivity in the detached retina and dilated vessels, and VEGF immunoreactivity in macrophages infiltrating the sub retinal proliferative tissue (9).

\section{Clinical findings and differential diagnoses}

Clinically, most cases present with a unilateral progressive loss of vision, strabismus or leukocoria; this makes unilateral retinoblastoma an important differential 
diagnosis since the two conditions appear in the same age group, with clinical features that overlap (3). Currently, a handheld portable spectral-domain optical coherence tomography (OCT) system is being used as as a novel and critical intraoperative tool in differentiating Coats disease from diffuse retinoblastoma and other mimicking conditions; it also helps to monitor the treatment response in Coats disease (10).

Coats disease affects mostly young children who cannot indicate their symptoms; it is therefore usually detected in advanced stages with fovea involvement. Awareness of the differential diagnosis of leucokoria by the ophthalmologist during ophthalmoscopy is crucial in identifying conditions like Coats' disease, toxocara

endophthalmitis, persistent hyperplastic primary vitreous (PHPV) and Norrie disease before eye enucleation for retinoblastoma.

PHPV and toxocara endophthalmitis are other differential diagnoses of Coats' disease which grossly mimic endophytic retinoblastoma and microscopically, they show vitreous fibrosis and vascularisation. Coats' disease, on the other hand, mimics exophytic retinoblastoma (3). The other differential diagnosis of Coats' disease is Norrie disease (8).

Table 1 Differences between Coats disease and Norrie disease.

\begin{tabular}{|c|c|c|}
\hline Features & Coats' Disease & Norrie Disease \\
\hline Mutation & $\begin{array}{l}\text { NDP (Xp11.2) Somatic } \\
\text { Mutation }\end{array}$ & $\begin{array}{l}\text { NDP (Xp11.3) Germ-line } \\
\text { Mutation }\end{array}$ \\
\hline $\begin{array}{l}\text { Age of onset of } \\
\text { symptoms/signs }\end{array}$ & $\begin{array}{l}\text { Childhood, sometimes adult } \\
\text { onset of blindness }\end{array}$ & $\begin{array}{l}\text { Early infancy, neonatal } \\
\text { or antenatal (in utero } \\
\text { ultrasonography) clinical } \\
\text { manifestation }\end{array}$ \\
\hline Sex ratio & Male: Female $>3: 1 .(2 ; 6)$ & Exclusively Males \\
\hline Familial characteristics & No familial predilection & Familial predilection \\
\hline Signs and symptoms & $\begin{array}{l}\text { Unilateral }(80 \%) \text { leukocoria } \\
\text { and/or strabismus and loss of } \\
\text { vision }\end{array}$ & $\begin{array}{l}\text { Bilateral leukocoria and/or } \\
\text { strabismus and loss of vision } \\
\text { Peripheral venous insufficiency } \\
\text { Mental retardation } \\
\text { Sensorineural deafness. }\end{array}$ \\
\hline Complications & Glaucoma, cataract & Glaucoma, cataract \\
\hline
\end{tabular}

\begin{tabular}{|l|l|}
\hline Gross findings & Retrolental whitish mass \\
\hline Histology & Vascular telangiectasis \\
& PAS-positive exudates \\
& Vacuolation, cholesterol cleft \\
& Retinal detachment, \\
& Gliosis \\
\hline
\end{tabular}

Norrie disease is an $\mathrm{X}$-linked recessive disorder characterized by congenital bilateral blindness due to degenerative and proliferative changes of the retina and optic nerve in males; it is caused by a germ-line mutation in Norrie Disease Protein (NDP) gene encoding for norrin, located on chromosome Xp11.3; the norrin

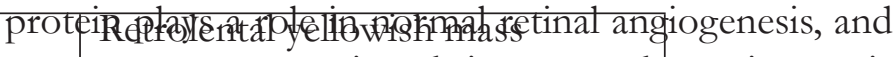
some Mportsstrogestits role in non-ocular angiogenesis (8). Children affected biv Norrie disease present with blindness at birth prearly infancy (8), because it results from rerm-line $N D P$ mutation, in contrast to Coats diseasegwhich results from a somatic NDP mutation. Table 1 summarizes the differences between Coats' disease and Norrie disease.

\section{Staging and management of Coats' disease}

Coats' disease progresses gradually and affects central vision. When Coats' disease is detected early, some level 
of vision can typically be restored. If not detected until its late stages, complete loss of vision can occur and enucleation may be necessary.

Five stages of Coats' disease are recognized (11), but published data show differences in staging criteria, as presented in table 2.

Table 2 Staging criteria and management of Coats' disease

\begin{tabular}{|c|c|c|c|}
\hline Staging Criteria & $\begin{array}{l}\text { Management } \\
\text { option of choice }\end{array}$ & $\begin{array}{l}\text { Stage accord } \\
\text { authors }\end{array}$ & o different \\
\hline $\begin{array}{l}\text { Shields et al. (11), Brinton et al. } \\
\text { (12), Kase et al. (9) }\end{array}$ & Kase et al. (9) & $\begin{array}{l}\text { Shields et al. } \\
\text { (11) }\end{array}$ & $\begin{array}{l}\text { Brinton et al. } \\
\text { (12) }\end{array}$ \\
\hline Retinal telangiectasia only & \multirow{5}{*}{$\begin{array}{l}\text { Cryotherapy; laser } \\
\text { photocoagulation; } \\
\text { Anti-VEGF agent } \\
\text { injection into the } \\
\text { vitreous }\end{array}$} & Stage 1 & Stage 1 \\
\hline $\begin{array}{l}\text { Telangiectasia and extrafoveal } \\
\text { exudation }\end{array}$ & & Stage $2 \mathrm{~A}$ & \multirow[t]{2}{*}{ Stage 2} \\
\hline Telangiectasia and foveal exudation & & Stage $2 \mathrm{~B}$ & \\
\hline $\begin{array}{l}\text { Extrafoveal subtotal exudative retinal } \\
\text { detachment }\end{array}$ & & $3 \mathrm{~A}(\mathrm{i})$ & \multirow[t]{2}{*}{ Stage 3} \\
\hline $\begin{array}{l}\text { Foveal subtotal exudative retinal } \\
\text { detachment }\end{array}$ & & $3 \mathrm{~A}$ (ii) & \\
\hline Total exudative retinal detachment & $\begin{array}{l}\text { Surgical retinal } \\
\text { reattachment; } \\
\text { Anti-VEGF agent } \\
\text { injection into the } \\
\text { vitreous }\end{array}$ & $3 \mathrm{~B}$ & \multirow[t]{2}{*}{ Stage 4} \\
\hline $\begin{array}{l}\text { Total retinal exudative detachment } \\
\text { and glaucoma }\end{array}$ & Enucleation & Stage 4 & \\
\hline $\begin{array}{l}\text { Advanced end-stage disease, with } \\
\text { cataract or phthisis bulbi }\end{array}$ & $\begin{array}{l}\text { Observation / } \\
\text { enucleation }\end{array}$ & Stage 5 & Stage 5 \\
\hline
\end{tabular}

The staging system according to Shields $e t$ al. seems to be the most accepted (6). Other conservative therapeutic methods include intravitreal injections of steroids or vascular endothelial growth factor (VEGF) inhibitors $(6 ; 9 ; 12)$.

\section{Tanzania data}

No other case of Coats disease had been reported in Tanzania. The review of all eye enucleation cases received at $\mathrm{MNH}$ from 2009 to 2011 revealed no other case of Coats disease. Table 3 shows the disease distribution in eyes enucleated at $\mathrm{MNH}$ department of Paediatrics from January 2009 to December 2011.

Table 3 Distribution of eye enucleation paediatric cases at MNH, 2009-2011

\begin{tabular}{|l|l|l|l|l|l|}
\hline Year & $\begin{array}{l}\text { Eye enucleation } \\
\text { in children }(<\mathbf{1 5} \\
\text { years of age })\end{array}$ & Retinoblastoma & $\begin{array}{l}\text { C o a t s } \\
\text { Disease }\end{array}$ & Lymphoma & $\begin{array}{l}\text { Non-specific } \\
\text { inflammation }\end{array}$ \\
\hline 2009 & 28 & 24 & 0 & 2 & 2 \\
\hline 2010 & 29 & 26 & 0 & 1 & 2 \\
\hline 2011 & 60 & 53 & 1 & 2 & 4 \\
\hline Total & 117 & 103 & 1 & 5 & 8 \\
\hline
\end{tabular}


Concerning our case, the disease was at early stage 4 characterized by total retinal detachment and signs of early glaucoma, that is, pain, proptosis, retinal gliosis and optic nerve mild atrophy. The optic disc cupping could not be assesses. The clinical presentation was strongly suggestive of unilateral retinoblastoma. The telangiectatic vessels depicted on B-scan ultrasonography may be also found in some cases of intraocular retinoblastoma (3). Radiologic examinations may reveal calcifications in either retinoblastoma or Coats disease. Enucleation was justified by the total retinal detachment and signs of glaucoma $(11 ; 12)$.

\section{Conclusion}

Coat's disease is a challenging differential diagnosis of unilateral retinoblastoma. Its clinical recognition at early stages leads to the salvage of the vision of the involved eye. Clinicians, radiologists and pathologists should keep in mind the possibility of this disease when investigating for retinoblastoma, to avoid unnecessary eye enucleation.

\section{Funding Support}

None

\section{Competing interests}

None to declare.

\section{Contributors}

JNK did the grossing of the specimen. TWM processed the specimen. TS was responsible for the acquisition of clinical data. PM, JNK, BR and TWM did the histopathological evaluation of the case. BR assisted in the acquisition of clinical data and prepared the manuscript. JNK and PM critically approved the manuscript.

\section{Acknowledgements}

We recognize the pivotal role played by the International Network for Cancer Treatment and Research (INCTR) through its iPath programme, in facilitating the online discussion of this case.

\section{References}

1. Coats G. Forms of retinal disease with massiveexudation. $\mathrm{R}$ Lond Ophthal Hosp Rev
1908;17:440-525.

2. Fernandes BF, Odashiro AN, Maloney S, Zajdenweber ME, Lopes AG, Burnier MNJr. Clinicalhistopathological correlation in a case of Coats' disease. Diagn Pathol 2006;1(24), doi:10.1186/17461596-1-24 [published Online First: 30 August 20067.

3. Shields CL, Uysal Y, Benevides R, Eagle RC Jr, Malloy B, Shields JA. Retinoblastoma in an Eye with Features of Coats' Disease. I Pediatr Ophthalmol Strabismus 2006;43:313-315.

4. Black GCM, Perveen R, Bonshek R, Cahill M, Clayton-Smith J, Lloyd, et al. Coats' Disease of the Retina (Unilateral Retinal Telangiectasis) Caused by Somatic Mutation in the NDP Gene: A role for Norrin in retinal Angiogenesis. Hum Mol Genet 1999;8(11):2031-2035.

5.Shields JA,Shields CL,HonavarSG,DemirciH.Clinical variations and complications of Coats disease in 150 cases: The 2000 Sanford Gifford Memorial Lecture. Am J Ophthalmol 2001;131(5):561-571.

6. Mulvihill A, Morris B. A population-based study of Coats disease in the United Kingdom. Eye 2010;24:1802-1807.

7. Nyamori JM, Kimani K, Njuguna MW, Dimaras H. The incidence and distribution of retinoblastoma in Kenya. Br J Ophthalmol 2012;96:141-143.

8. Michaelides M, Luthert PJ, Moore AT. Norrie disease and peripheral venous insufficiency. BrJ Ophthalmol 2004;88:1475-1481.

9. Kase S, Rao NA, Yoshikawa H, Fukuhara J, Noda K, Kanda A, Ishida S. Expression of vascular endothelial growth factor in eyes with Coats' disease. Invest Ophthalmol V is Sci. 2013;54(1):57-62.

10. Henry CR, Berrocal AM, Hess DJ, Murray TG. Intraoperative spectral-domain optical coherence tomography in coats' disease. Ophthalmic Surg Lasers Imaging 2012;43:e80-4.

11. Shields JA, Shields CL, Honavar SG, Demirci H, Cater J. Classification and management of Coats disease. Am J Ophthalmol 2001;131(5):572-583.

12. Brinton JP, Jensen LE, Folk JC. Coats Disease: 11year-old male with poor vision in left eye. EyeRounds. org. [Online] December 30, 2009. [Cited: May 06, 2012.] http://www.eyerounds.org/cases/100-Coats-

Disease.htm. 